\title{
RESEARCH REPORT \\ Crosslinguistic evidence for a strong statistical universal: Phonological neutralization targets word-ends over beginnings
}

\section{ANDREW WEDEL}

University of Arizona
ADAM USSISHKIN

University of Arizona
ADAM KING

University of Arizona

\begin{abstract}
We report a statistical test of a long-standing hypothesis in the literature: that phonological neutralization rules are more common at the ends of lexical domains than the beginnings (Houlihan 1975 et seq.). We collected descriptive grammars for an areally and genetically diverse set of fifty languages, identified all active phonological rules that target the edge of a lexical domain (root, stem, word, phrase or utterance), and further coded each rule for whether it was phonemically neutralizing, that is, able to create surface homophony. We find that such neutralizing rules are strongly, significantly less common at the beginning of lexical domains relative to ends, and that this pattern is strikingly consistent across all languages within the dataset. We show that this pattern is not an artifact of a tendency for syllable codas to be a target for phonological neutralization, nor is associated with a suffixing or prefixing preference. Consistent with previous accounts, we argue that this pattern may be ultimately based in the greater average information content of phonological categories early in the word, which itself is a consequence of incremental processing in lexical access.
\end{abstract}

Keywords: Phonology, Typology, Neutralization, Lexical Processing

* Many thanks to Jonathan Geary and Jaycie Ryrholm Martin for assistance with initial data collection, Kathleen Houlihan, Jeff Mielke and multiple academic audiences for thoughtful questions and comments.

1. INTRODUCTION. Listeners identify words incrementally at the sub-lexical level, continually updating hypotheses about the identity of the word as its phonetic signal unfolds (Tyler 1984; Marslen-Wilson and Zwitserlood 1989; Allopenna et al. 1998; Fernald et al. 2001; Dahan et al. 2001, Magnuson et al. 2007). If we conceptualize the 'information' carried by each phonetic cue in terms of the change it introduces in the probabilities of competing alternatives (Shannon 1949), then phonetic cues earlier in the word on average contribute more information to lexical identification than phonetic cues later in the word (e.g. van Son \& Pols 2003, Magnuson et al. 2007). As an illustration, consider the English word contrast. Phonetic cues to the initial / $/ \mathrm{k} /$, if perceived accurately, provide information to the listener that help exclude the many words in the English lexicon which begin with a segment other than $/ \mathrm{k} /$. Cues to the final $/ \mathrm{t} /$ contribute considerably less information to lexical access because the probability of the word contrast is already high given the context of the previous sequence [kantıæs-] in the signal (see Van Son \& Pols (2003) for discussion of the information content of phonetic cues in lexical access).

Correspondingly, language users have been shown to pay more attention to word-initial information over information presented later in the word. Miller and Friedman (1957) presented participants with written English sentences in which words contained blank spaces in lieu of some letters, and asked participants to guess the letters in varying blank positions. Responses were most accurate when the blank positions were word-medial, next most accurate when word-final, and least accurate when blank positions were word-initial. Bruner and O'Dowd (1958) presented participants with printed English words and asked them to identify the words. The words were presented with two adjacent letters reversed; more identification errors occurred when the first two letters were reversed than when the last two letters were reversed; more errors occurred when the last two letters were reversed than when two medial letters were reversed. Based on these results, and their own work on the tip-of-the-tongue phenomenon, Brown and McNeill (1966) proposed 
that word beginnings are more informative than word endings, and that word endings are more informative than the middle of words. This proposal was tested by Nooteboom (1981), who showed that when presented with either initial or final word fragments, Dutch listeners identified words considerably more accurately based on exposure to initial fragments.

A number of phonologists working in different traditions have argued that the distribution of phonological rules in grammars should be shaped by the greater information provided by early cues and listeners' correspondingly greater attention to them. Houlihan (1975) used these considerations in conjunction with a large survey of phonological rules to argue that word-initial position should tend to host a greater number of contrasts than word-final position, and that rules that neutralize contrasts should be limited to word-final position. Likewise, Nooteboom's (1981) findings of greater listener attention to word beginnings led him to predict, "(1) in the initial position there will be a greater variety of different phonemes and phoneme combinations than in word final position, and (2) word initial phonemes will suffer less than word final phonemes from assimilation and coarticulation rules" (Nooteboom 1981:422; parallel arguments were made by Houlihan and Iverson (1979) and Taft (1984)). Similarly, Hume (1998) predicted that metathesis will be less prevalent at word beginnings in order to be less disruptive to word recognition. In a subsequent study, Mielke and Hume (2001) surveyed 54 languages with synchronic metathesis processes and found that as predicted, metathesis was much more common at the end of words than at the beginnings. (Note that for these authors, as well as for our purposes here, wordinitial/final position can potentially refer to any level of phonological structure, such as segment, syllable, foot, etc.)

Based in the same word-level processing asymmetries (e.g., Taft 1984 as cited in Smith 2004), word-level phonological asymmetries were addressed in Optimality Theory by Beckman (1997) and Smith (2004), primarily through a proposed expansion of the inventory of positionspecific constraints. Beckman argued that root-initial position is privileged, based on the greater number of contrasts in this position in the vowel-harmony system of Shona. Smith (2004) argued that "psycholinguistically strong" positions, such as word-initial syllables, are under functional pressure to host more contrasts. These proposals make reference to the same sort of survey data used earlier by Houlihan and colleagues (1975, Houlihan \& Iverson 1979, Taft 1984).

More recently, a broad range of corpus and experimental work has provided strong evidence that phonetic cues that provide less information to the listener in lexical access are more prone to reduction in usage and vice versa (e.g., Cohen Priva 2015, Seyfarth et al. 2016, Wedel et al 2018). Hall et al. $(2016,2018)$ have argued that this tendency for speakers to preferentially reduce lower information phonetic creates the effect of an output-oriented filter on the evolution of phonologies, where rules which decrease information in the speech signal tend to evolve in positions that already convey less lexical information to listeners, such as word ends and unstressed syllables.

1.1 THE GOAL OF THIS STUDY. Despite all this previous work to explain a presumed crosslinguistic asymmetry in edge-based contrast patterns, to our knowledge the hypothesis that there exists such an asymmetry has not been rigorously tested using modern statistical approaches. For example, the investigations reviewed above are based on data that was obtained by searching the literature for aggregated descriptions of particular phonological process types or positions. Houlihan (1975) for example based her in-depth study on a large set of word-initial/final, strengthening/weakening rules collected from the literature (see also Houlihan \& Iverson 1979, Taft 1984, Beckman 1997, Smith 2004). Here, our goal is to contribute to this area of research 
through a more typologically and statistically well-controlled test of the hypothesis, achieved through assembly and analysis of grammars for a large, typologically-balanced set of languages, where the choice to include a grammar in the dataset is made prior to analysis with respect to the hypothesis. We limit ourselves here to testing a single, conservatively defined formulation of the proposed asymmetry: that phonemically neutralizing rules (i.e., those which can potentially create surface homophony) are relatively more likely to target the ends of lexical domains than the beginnings, as argued in Houlihan 1975. We chose this simple operationalization of the broader hypothesis described above because it can be reliably addressed using information provided in descriptive grammars of languages.

The dataset was assembled by collecting grammars for a genetically and areally diverse set of fifty languages. Within each grammar, we identified all phonological rules which targeted either the beginning or end of a lexical domain, and then further coded each rule for whether it was phonemically neutralizing or not. We tested the hypothesis that neutralizing rules are more likely to target lexical domain ends than beginnings, relative to the set of rules as a whole. We additionally tested whether (i) any tendency for neutralizing rules to preferentially target wordends could be explained through a bias toward neutralization in syllable codas, or (ii) through a suffixing-bias in the languages within the dataset.

2. METHODS.

2.1. ASSEMBLING A DATASET. The process of assembling a coherent dataset of phonological rules from disparate source grammars requires many contingent decisions at different levels (i.e., there are many 'researcher degrees of freedom'; Simmons et al. 2011, Roettger 2019). To maximize the transparency of our process, in this section we provide a detailed description of our heuristic for building the dataset.

We set a target of including rules from fifty descriptive grammars from a genetically and areally diverse sample (see Figure 1 and the supplemental materials). The goal of fifty grammars was established shortly after the beginning of the project to avoid drift in our sample size in response to analysis outcomes. We located grammars through the University of Arizona library, initially by browsing in the physical stacks, and then increasingly by searching the library website for dissertations available online with the word 'grammar' in their titles. We identified grammars for inclusion in the dataset on the basis of a number of soft criteria: we chose grammars which were based on work with native speakers, which were primarily descriptive (that is, not undertaken in the overt service of testing a particular theory or claim), and that contained phonology sections describing at least two rules that target a lexical domain edge (see below). This latter restriction was included because our research questions did not include testing whether languages are likely to contain rules targeting an edge of a lexical domain per se, but rather whether such rules are distributed unevenly over domain sides in relation to whether they are neutralizing versus non-neutralizing. Only seven initially-examined grammars which otherwise fit our requirements were not included in the dataset due to the absence of at least two rules fitting these criteria.

As we progressively included more grammars in the dataset, we began to focus our search within particular areas or language families, and on affix preference, in order to achieve a reasonable balance among these factors in the final dataset (see below). All choices of whether to include a grammar in the dataset were finalized before undertaking any analysis beyond that required to identify at least two rules of any sort targeting the edge of a lexical domain. The median number of rules per language in the final dataset is five. 
2.2. PHONOLOGICAL RULE INCLUSION CRITERIA. We identified every phonological rule in each grammar that included the edge of a lexical domain in its environmental specification and which resulted in a surface phonological alternation. We did not include rules describing static morpheme-structure constraints, that is, patterns that are not apparent through alternations. Because we are interested in rules that potentially neutralize lexical contrasts, we defined 'lexical domain' to be any linguistic unit including a content morpheme, such as a root, stem, word, phrase or utterance. We did not include any rules that solely apply to the edges of functional items such as affixes or grammatical morphemes. Recall that the overarching hypothesis is that contrast-reducing rules tend not to develop in domain-initial positions because those positions are most informative in lexical access. Because functional items are in general highly predictable, we expect that contrast-reducing rules will not be avoided for these morpheme types.

We included rules which were operationally defined by the author of the grammar at the syllable level if the only surface alternations resulting from the rule are at lexical domain edges as defined above. (Rules of this type in this dataset are exclusively coda-restrictions, and inclusion of these rules did not affect our main conclusion; see results below.) We included rules whose application is specific to major word classes, such as noun or verb, but to keep the dataset focused on broader phonological patterns that do not also provide highly specific lexical or morphosyntactic information, we did not include rules that apply only to a narrow range of lexical items or only in specific morpho-syntactic contexts. As an example, we did not include processes associated with the class 9/10 noun prefix / $\mathrm{N}$-/ in Chichewa (Downing \& Mtenje 2017), because these processes are specific to this morpheme, rather than applying over the language as a whole. Finally, if a grammar reported a number of patterns separately which overlapped significantly in their structural descriptions or outputs, we conservatively chose to only record a single representative rule in the final dataset to avoid possible overcounting. As an example, the grammar for Ayutla Mixe reports a complex pattern of vowel fronting and/or raising before word-final /j/ (Romero 2008). These patterns cannot be straightforwardly described in a single rule, but they all share the same conditioning environment and can be potentially seen as a unified chain-shift process, so we recorded this set of Ayutla Mixe chain shift rules in the dataset as one summary rule. We note that no sets of rules were collapsed in this way which were coded as both (i) neutralizing and (ii) as targeting the beginning of a lexical domain. This is relevant because collapsing rules in this cell of the data could inadvertently introduce an anti-conservative bias with respect to the tested hypothesis.

Authors of grammars bring their own approaches, skills and traditions to the complex task of describing a phonological system. In the face of this diversity, we worked to build an internally consistent dataset through employing our best judgment about how to understand each pattern as described (for another example of the complexities of building a phonological rule dataset, see discussion in Brohan \& Mielke 2018). If, however, we were left with too much uncertainty about how to code a pattern, we erred on the side of not including it in the dataset. The final dataset comprised 237 rules from 50 languages distributed over 37 top-level families and 21 AUTOTYP areas (Bickel \& Nichols 2017; Figure 1, Table 1). 44 of the languages in the dataset contained at least one neutralizing rule (see Figure 3 below). 
Figure 1. Locations of the fifty languages in the dataset. There are 8 languages in the dataset that are exclusively prefixing (blue), 13 which are exclusively suffixing (yellow); the rest allow both prefixes and suffixes (red).

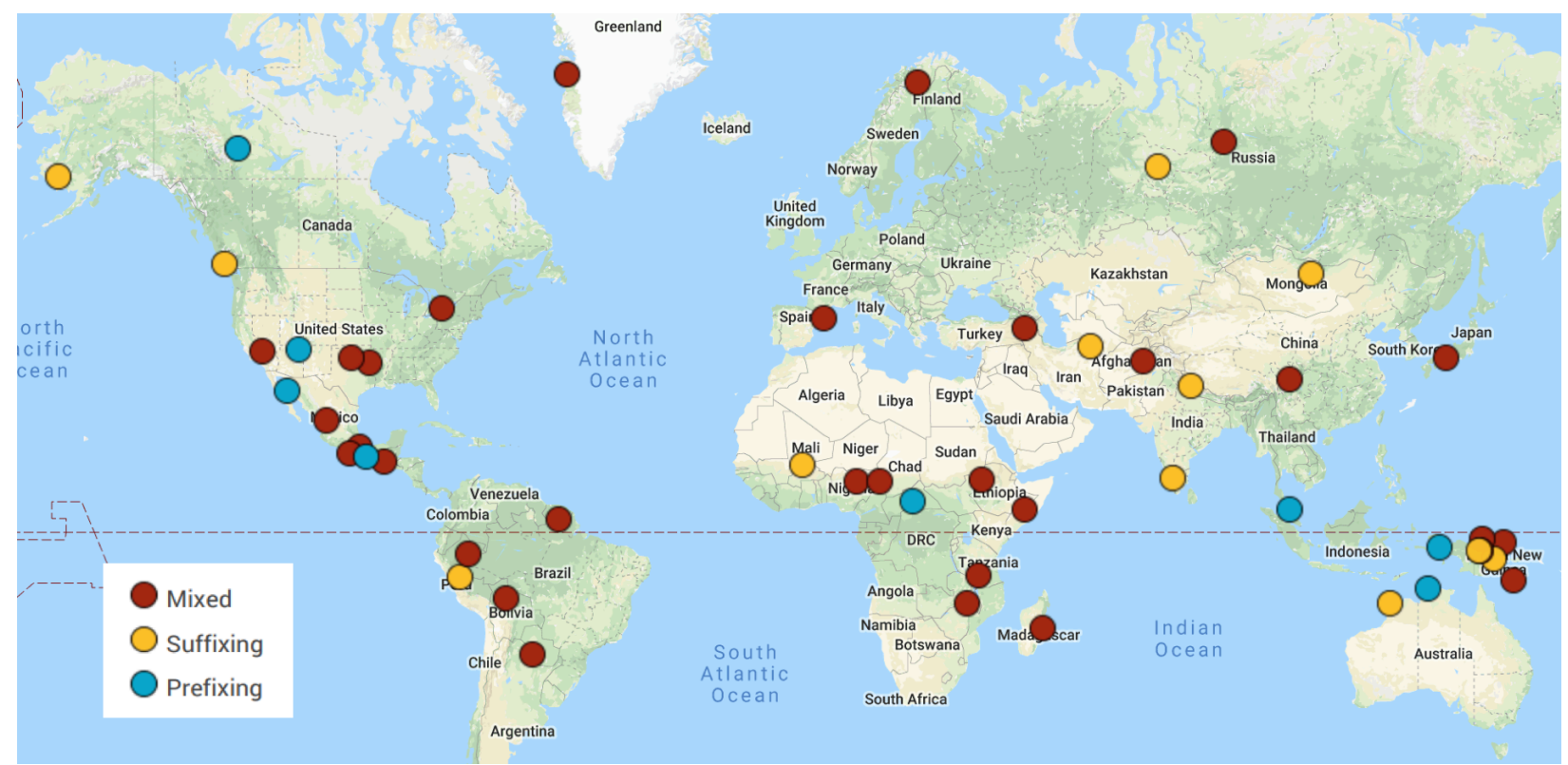


Table 1. Representative examples of rules in the dataset

Language

\begin{tabular}{|c|c|c|}
\hline \multirow{4}{*}{$\begin{array}{l}\text { Beginning, } \\
\text { Non-neutralizing }\end{array}$} & a. Pashai & [?] epenthesized before word-initial vowel. \\
\hline & b. Khalhka & /g/ surfaces as [q] word-initially before a back \\
\hline & Mongolian & vowel. \\
\hline & c. Ayutla Mixe & $/ \mathrm{w} /$ is optionally strengthened to [b] word initially. \\
\hline \multirow{3}{*}{$\begin{array}{l}\text { Beginning, } \\
\text { Neutralizing }\end{array}$} & d. Central Yupik & Continuants are devoiced in word-initial position. \\
\hline & e. Yeri & /u/ is optionally deleted word-initially. \\
\hline & f. Turkmen & $\begin{array}{l}\text { /b, d, g/ devoice after a voiceless homorganic stop; } \\
\text { can occur across word boundaries. }\end{array}$ \\
\hline \multirow{3}{*}{$\begin{array}{l}\text { End, } \\
\text { Non-neutralizing }\end{array}$} & g. Movima & $\begin{array}{l}\text { A copy of the previous vowel is epenthesized pre- } \\
\text { pausally after [?]. }\end{array}$ \\
\hline & $\begin{array}{l}\text { h. Southeastern } \\
\text { Tepehuan }\end{array}$ & $/ \mathrm{v} /$ is devoiced to [f] word-finally. \\
\hline & i. Japanese & $\begin{array}{l}\text { Word-final high vowels are devoiced when } \\
\text { preceded by a voiceless consonant. }\end{array}$ \\
\hline \multirow{3}{*}{$\begin{array}{l}\text { End, } \\
\text { Neutralizing }\end{array}$} & j. Gumuz & Voiced stops devoice word-finally. \\
\hline & k. Bardi & Vowels optionally delete word-finally. \\
\hline & 1. Somali & Word-final /m/ surfaces as [n]. \\
\hline
\end{tabular}

2.3. ANALYSIS. We coded all phonological rules in the dataset for the following properties:

DOMAIN SIDE (beginning vs. end)

We coded each rule for the side of a domain at which application of the rule creates a surface representation different from the underlying representation. The majority of the rules we found (220/237) target a segment at the edge of the surface representation, as in a word-final devoicing rule. A smaller number of rules (17/237) target an edge syllable, as in a rule that neutralizes a vowel length contrast in word-final closed syllables. Removal of the edge syllable-targeted rules from the dataset does not alter the results (not shown).

RULE TYPE (neutralizing vs. non-neutralizing)

We coded for whether a rule was potentially neutralizing at a phonological level; that is, whether it could potentially create homophony in surface lexical forms based on the reported phonotactics of the language. (We did not attempt to identify whether a neutralizing rule results 
in any actual surface homophony in the language; see discussion.) For example, a rule optionally deleting word-final vowels in Bardi is coded as a neutralizing rule because multiple possible underlying forms could result in the same surface form (Table 1, k). Conversely, a rule in Southeastern Tepehuan that devoices word-final /v/ to [f] is coded as non-neutralizing, because /f/ does not exist as a phoneme in Southeastern Tepehuan, allowing [f] to be mapped by a listener uniquely back to underlying /v/ (Table 1, h). Out of the 237 total rules in the dataset, 107 are coded as neutralizing.

Note that this division of rules into 'phonologically neutralizing' and 'non-neutralizing' is a coarse way to bin the data relative to the overarching hypothesis, which is that the set of factors influencing evolution of phonological patterns includes a bias toward maintaining effective transmission of lexical information in usage (Wedel 2012, Hall et al. 2016, 2018). For example, it is likely that some of the patterns that are described as phonologically neutralizing in our grammars are in fact incompletely neutralizing at a phonetic level, allowing the underlying contrasts to be recovered to some degree by listeners (e.g., Warner, Jongman, Sereno \& Kemps 2004). Conversely, many rules which we have coded as non-neutralizing are likely to reduce the perceptibility of underlying contrasts; an example would be word-final vowel devoicing. Nonetheless, the rules that are coded as phonemically neutralizing should on the whole have a greater potential to reduce lexical contrast information in the phonetic signal relative to those coded as non-neutralizing. See Table 1 for representative examples of rules in the dataset coded as neutralizing and non-neutralizing; see the supplemental materials for a complete list.

\section{CODA STATUS (coda vs. non-coda)}

To allow us to ask whether an asymmetry in the distribution of rules at the beginnings versus the ends of words can be accounted for by an asymmetry in the number and type of rules that involve syllable codas, we coded every rule for whether it deletes a coda, or modifies an underlying segment that surfaces as a coda. As examples, coda-modifying rules under this scheme include final consonant deletion, final consonant devoicing, or epenthesis of a final vowel which converts what would otherwise surface as a coda into an onset. Rules that are coded as not modifying underlying segments that would otherwise surface as codas include, for example, a final vowel deletion rule, or a rule that epenthesizes a glottal stop before word-initial vowels.

\section{AfFIX PREFERENCE (Suffixing, Prefixing, Mixed)}

Morpheme contact provides a context for phonological alternation. As expected given the wellknown typological suffixing preference (Greenberg 1957), we encountered more exclusively suffixing languages than prefixing languages as we assembled the dataset. To allow us to better assess whether affixing preference could account for any edge asymmetry in rules, as we neared the end of collection of grammars we intentionally sought out and included additional exclusively prefixing languages that otherwise fit our search criteria. The final dataset contains 31 rules from 7 exclusively prefixing languages, 52 rules from 12 exclusively suffixing languages, and 154 rules from 31 languages with both prefixes and suffixes. For these 'mixed' languages, we further coded them by their inflectional affixing bias as reported in the World Atlas of Language Structures (Dryer 2013). Among these mixed languages, the dataset contains 69 rules from dominant suffixing languages, 45 rules from dominant prefixing languages, and 40 
rules from languages with no identified preference. There were a small number of mixed prefixing/suffixing languages in our dataset which were not coded in WALS for inflectional affix preference. For these languages, we used our best judgment based on the information provided in the grammar to assign them to a category; when in doubt we coded them as having no identified preference. Figure 1 shows the areal distribution of languages by affix preference.

3. RESULTS. Figure 2 shows a graph of the number of rules in the dataset targeting the beginning versus ends of lexical domains, divided further into those rules that are coded as neutralizing versus non-neutralizing. An initial observation, which was not part of our hypothesis under consideration, is that there are more rules overall that target the ends of lexical domains than the beginnings. When we further compare rule types however, we can see that in this dataset the overall end-bias appears to be yet stronger for rules coded as neutralizing. This is consistent with the hypothesis that neutralizing rules are more likely to be defined at ends of lexical domains than other rule types. This tendency is robust as well within individual languages in the dataset: Of the 44 languages in the dataset which have at least one neutralizing rule, 42 have a greater number of neutralizing rules at domain ends than at domain beginnings (see Figure 3 and associated text below). 
Figure 2. Distribution of neutralizing and non-neutralizing rules by lexical domain sides
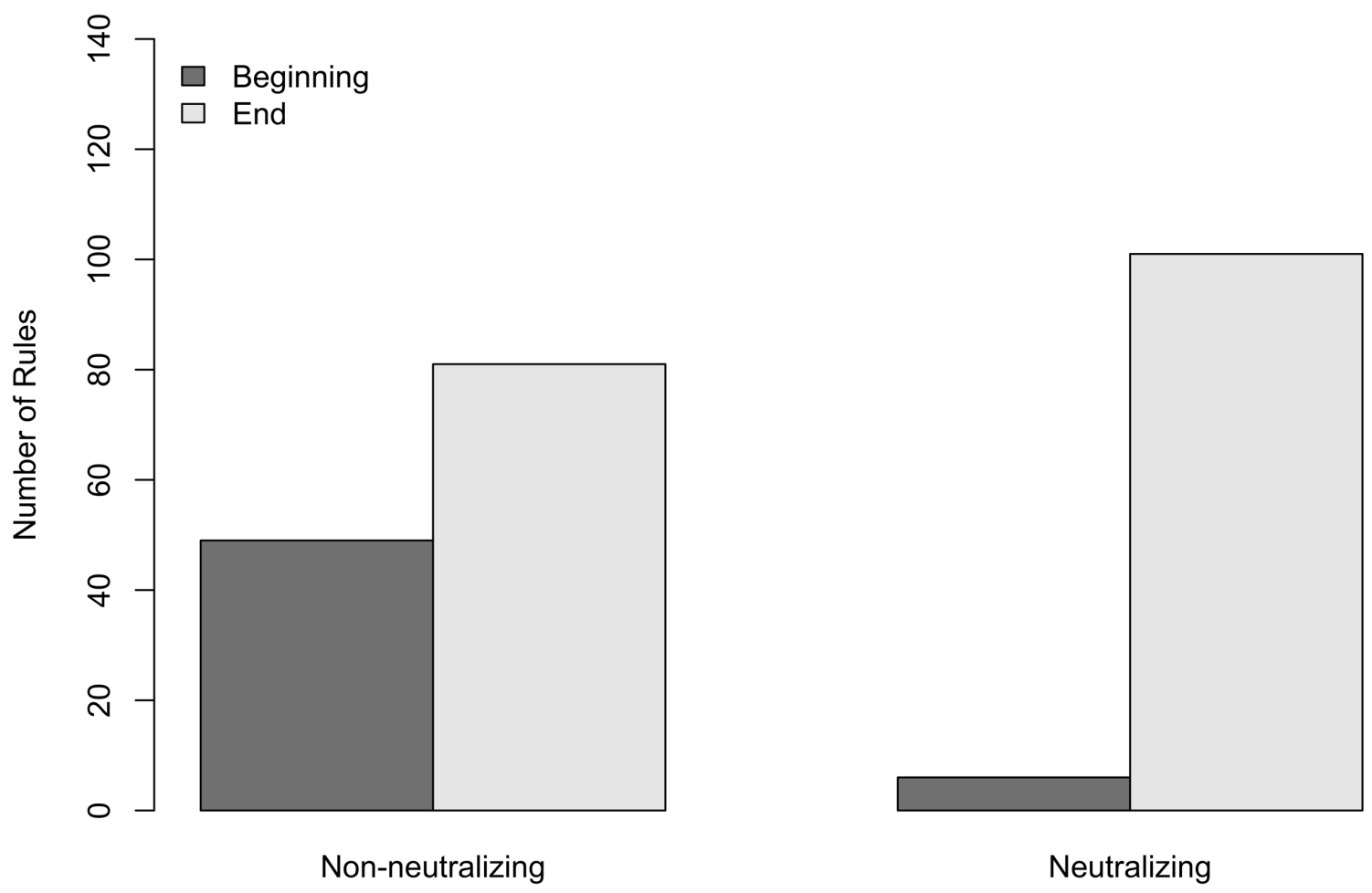

Rule Type

To explore this difference statistically, we used logistic mixed effects regression to analyze the distribution of rule types with respect to the side of the lexical domain to which they apply. In our primary analysis, we ask whether the fixed factor RULE TYPE (neutralizing vs nonneutralizing) significantly predicts the value of the dependent measure, DOMAIN SIDE (beginning vs end), and if so, if it is significant in the hypothesized direction: neutralizing rules should be relatively more common at the ends of lexical domains than beginnings, relative to nonneutralizing rules. We included AREA as coded in the AUTOTYP database (Bickel \& Nichols 2017), language FAMILY as coded in Glottolog (Hammarström et al. 2018) and LANGUAGE as random intercepts to address lack of independence in the data inherent in these groupings (Jaeger et al. 2011; LANGUAGE is nested within AREA and FAMILY). We used treatment coding of the RULE TYPE factor, with non-neutralizing as the reference level. The choice of coding-scheme does not influence the overall behavior of the model. We choose this particular coding scheme because it provides a more directly interpretable model output given the hypothesis we are testing (Schad et al. 2018). The model output is shown in Table 2 below. 
Table 2. Logistic model output

A

Fixed effects:

$\begin{array}{lrrrrr} & \text { Estimate } & \text { Std. Error } & \text { z value } & \mathrm{p} \text { value } \\ \text { (Intercept) } & 0.5258 & 0.2123 & 2.4766 & <.05 & * \\ \text { RULETYPE- } & & & & & \\ \text { Neutralizing } & 2.3392 & 0.4659 & 5.0208 & <.0001 & *\end{array}$

B. Random effects:

$\begin{array}{lrrr} & \text { Name } & \text { Variance } & \text { Std.Dev. } \\ \text { LANGUAGE: AREA } & \text { (Intercept) } & 7.338 \mathrm{e}-10 & 2.709 \mathrm{e}-05 \\ \text { LANGUAGE: FAMILY } & \text { (Intercept) } & 7.875 \mathrm{e}-09 & 8.874 \mathrm{e}-05 \\ \text { FAMILY } & \text { (Intercept) } & 0 & 0 \\ \text { AREA } & \text { (Intercept) } & 3.662 \mathrm{e}-02 & 1.913 \mathrm{e}-01\end{array}$

The fixed-effect intercept in the model represents the model's prediction for the probability that a rule coded as non-neutralizing will target the end of a lexical domain. The intercept is significantly positive (Table $2 ; \mathrm{p}<.05$ ), indicating that non-neutralizing rules are significantly more likely to target the ends of lexical domains. The model estimate for the fixed factor RULE TYPE is itself significantly positive $(p<.0001)$, which indicates that neutralizing rules are significantly even more likely to target the end of a lexical domain, relative to non-neutralizing rules. The model indicates that within this dataset, a rule is nearly twice as likely to target the end of a lexical domain than the beginning if it is non-neutralizing (0.63), but that it is about 20 times more likely to target an end if it is neutralizing (0.95). These model odds are consistent with the visual representation of the data in Figure 2.

The data is too sparse to allow us to include RULE TYPE as a random slope on the random intercept terms to control for possible asymmetries in behavior of RULE TYPE across these groupings. However, we can see graphically that the end-bias in neutralizing rules is highly consistent across all languages in the dataset. Figure 3 a shows the number of neutralizing rules in each language, plotted by how many of the rules target the beginning versus end of a lexical domain. Under the null hypothesis of no end-bias, we would expect languages to be randomly distributed above and below the diagonal line, which represents an equal number of neutralizing rules targeting each side. Instead, we see that while most languages have one or more neutralizing rules targeting a domain end, most languages have no neutralizing rules targeting a domain beginning, and no language has more than one. In fact, only one one out of the 50 languages falls above the line: the grammar for Stau reports a single neutralizing rule that optionally applies at the beginning of words produced in isolation. This shows that although there could be random subgroupings of the data in which the end-bias is varyingly strong, there is no plausible subgrouping at or above the level of LANGUAGE in which there could be a reversal of the bias, that is, a greater tendency for neutralizing rules to target lexical domain beginnings. Figure $3 \mathrm{~b}$ shows the same data separately for each AUTOTYP area. 
Figure 3a. Languages plotted by their number of beginning- versus end-targeting neutralizing rules. Points are jittered for better visualization.

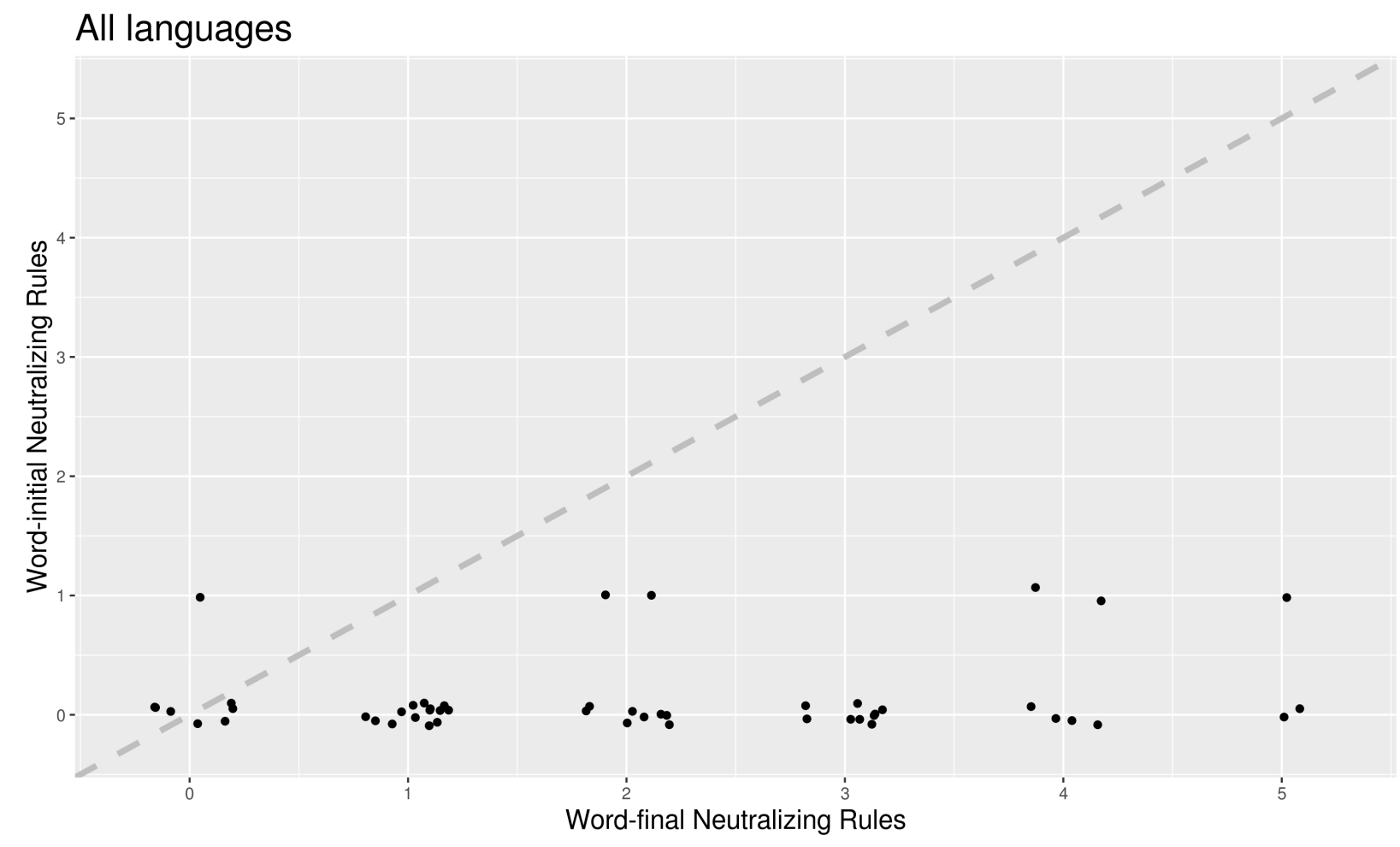


Figure 3b. Languages plotted by their number of beginning- versus end-targeting neutralizing rules, divided by AUTOTYP linguistic area. For this figure, the South and Central New Guinea areas were combined. Areas are ordered in the figure by approximate physical adjacency.

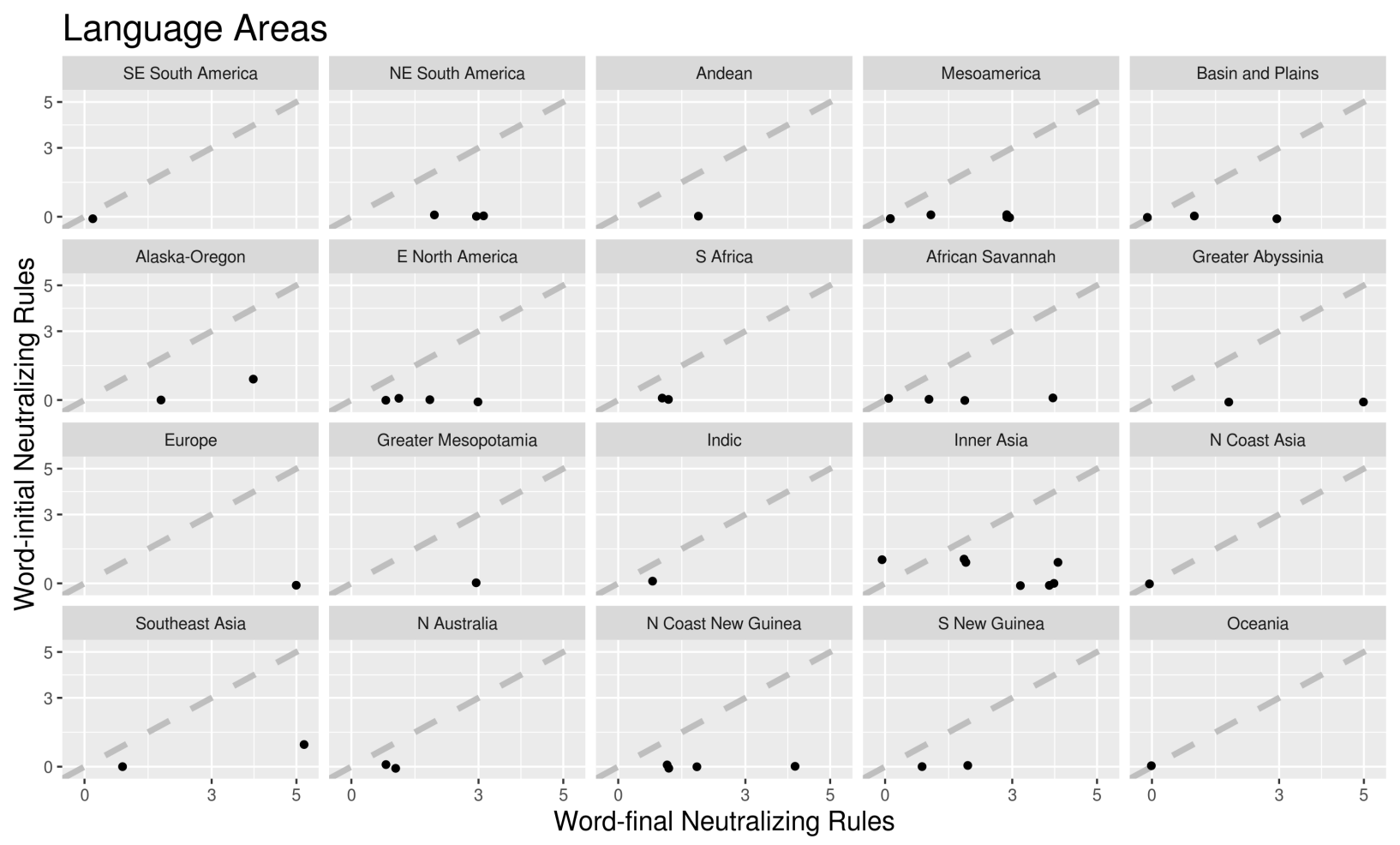

3.1. COUld THIS JUST BE ABOUT CODAS? Many of the neutralizing rules in this dataset target word-final coda consonants, for example through devoicing, deletion, or debuccalization. Consonants in coda position have been argued to be typologically more likely than onsets to be the target of phonological processes in general, and neutralizing processes in particular (Itô 1987, 2018). To ask whether the end-bias for neutralization we find in this dataset can be accounted for through a preponderance of coda-modifying rules, we created a binary factor coding rules for whether they delete or modify a surface coda (see Section 2 above). Rules coded as 'codamodifying' were exclusively found at the ends of lexical domains; while one can imagine a rule which could modify a coda at the beginning of a lexical domain, for example by modifying the coda in the word-initial syllable, no such rules are present in this dataset. Out of the 182 rules in the dataset that target the end of a lexical domain, $106(58 \%)$ were coded as modifying syllable codas. The remaining rules delete or modify syllable nuclei, or are epenthesis rules.

We use two strategies to ask whether the end-bias in neutralizing rules in this dataset can be accounted for by a greater tendency for codas to be the target of neutralizing rules. In the first, we focus on the subset of rules targeting lexical domain ends and ask whether coda modifying rules are more likely to be neutralizing than non-coda modifying rules - and find that they are not. In the second, we remove all coda-modifying rules from the dataset and ask whether the remaining rules still show a statistically significant end-bias for neutralizing rules - and find that they do. 
Among the set of end-targeted rules, there are 106 coda modifying rules and 76 non-coda modifying rules. Figure 4 illustrates that both non-coda modifying and coda modifying rules are about equally likely to be neutralizing. A logistic regression predicting RULE TYPE with the fixed factor CODA (with levels 'coda modifying' versus 'non-coda modifying'), with the same random effects structure used above, shows no significant predictive relationship between the two factors $(p>.05$; model output not shown). This indicates that within this dataset, there is no evidence that contrasts in word final codas are more likely to be neutralized than contrasts in word final vowels. This in turn indicates that the end-bias in neutralization in this dataset cannot be accounted for solely through coda modifying rules.

Figure 4. Proportions of coda or non-coda modifying rules which are neutralizing.

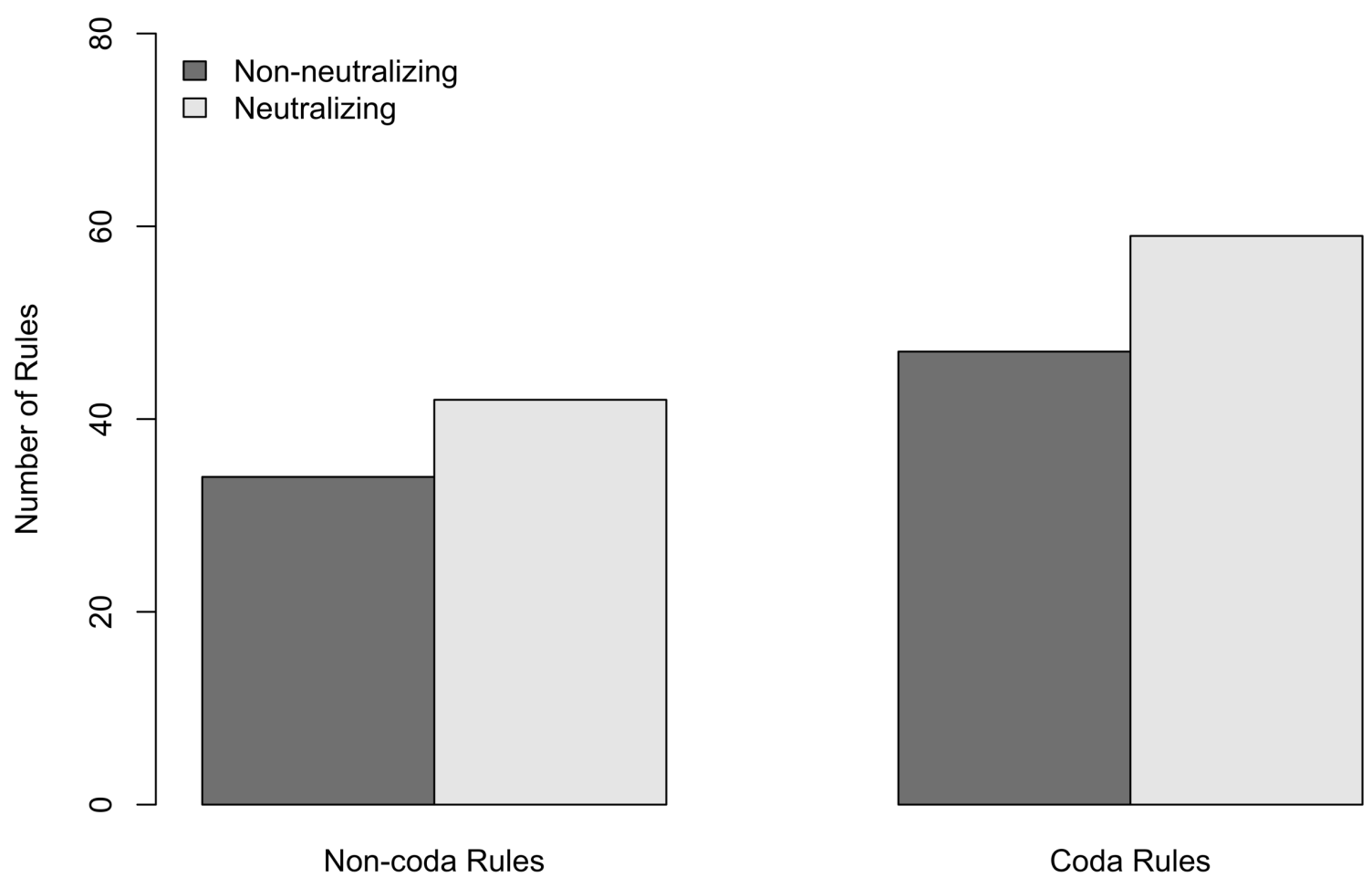

Rule Type

To ask whether the end-bias in neutralization for non-coda modifying rules remains statistically significant on its own, we removed all coda modifying rules from the dataset. 131 out of the original 237 rules in the dataset were retained; four languages were no longer represented in the dataset by virtue of only having rules that were coded as modifying codas. Figure 5 shows the distribution of these non-coda modifying rules, broken down by lexical domain side, and whether they are coded as neutralizing. In this restricted dataset, the nonneutralizing rules are no longer significantly more likely to be defined at the ends of lexical domains (Table $3 ; \mathrm{p}>.05$ ), but the end-bias for neutralizing rules remains significant $(\mathrm{p}<$ 
.0001 ), and the model estimate for the probability that a neutralizing rule will be defined at the end of a domain remains nearly the same as in the full dataset, at 0.91 . In keeping with the finding above that coda and non-coda modifying rules are equally likely to be neutralizing, this shows that the end-bias for neutralizing rules is similarly strong for both for coda and non-coda modifying rules. In summary, within this dataset a putative preference for neutralization of codas cannot explain the overall end-bias in neutralizing rules.

Figure 5. Distribution of the subset of neutralizing and non-neutralizing rules which do not modify codas by lexical domain sides.
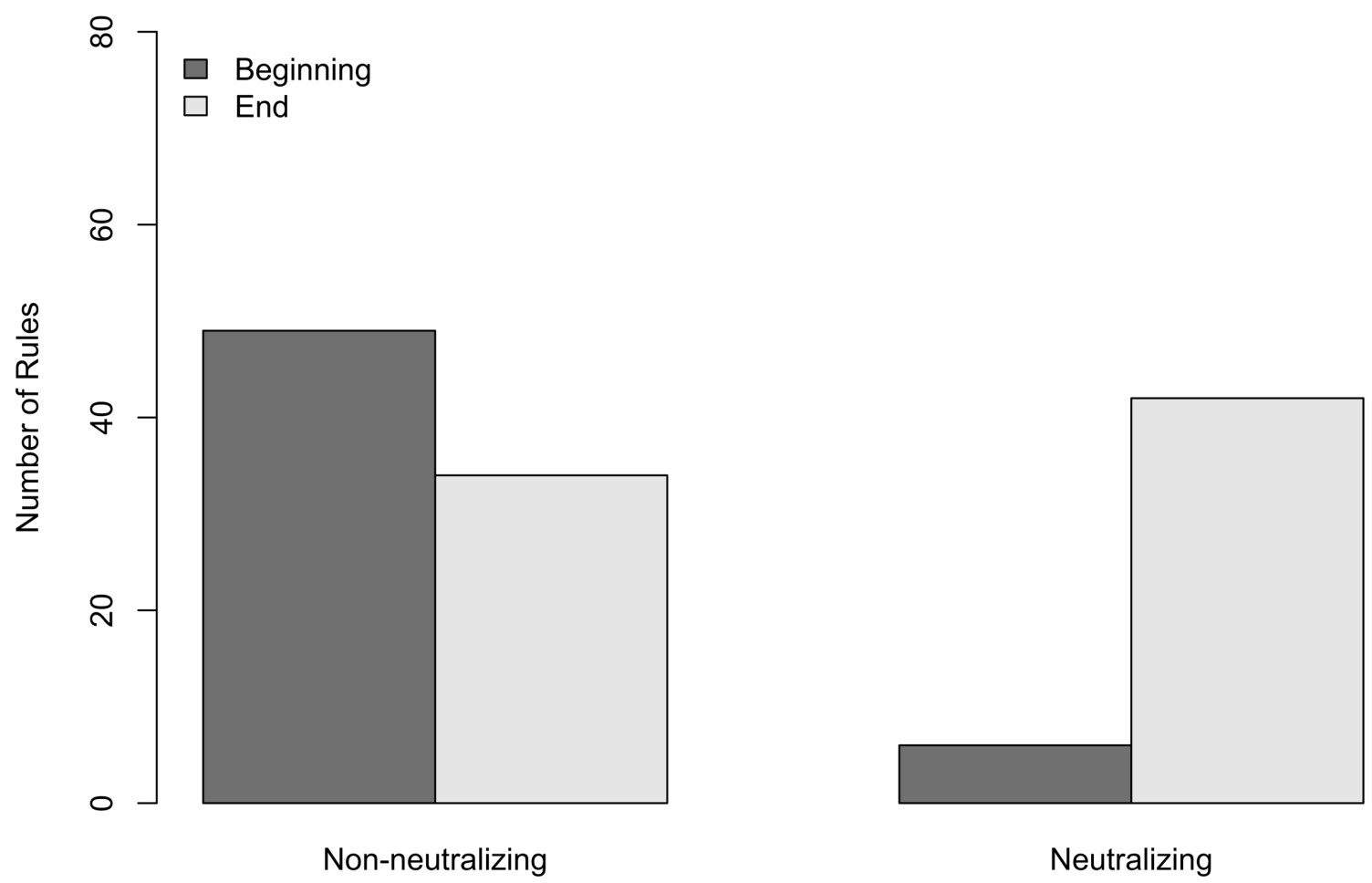

Rule Type 
Table 3. Model output for dataset without coda-modifying rules

A

Fixed effects:

$\begin{array}{lrrrrr} & \text { Estimate } & \text { Std. Error } & \mathrm{z} \text { value } & \mathrm{p} \text { value } \\ \text { (Intercept) } & -0.3119 & 0.2709 & -1.151 & >.05 & \\ \text { RULETYPE- } & & & & & \\ \text { Neutralizing } & 2.5010 & 0.5482 & 4.562 & <.0001 *\end{array}$

B. Random effects:

$\begin{array}{lrrr} & \text { Name } & \text { Variance } & \text { Std.Dev. } \\ \text { LANGUAGE: AREA } & \text { (Intercept) } & 1.004 \mathrm{e}-5 & 3.169 \mathrm{e}-03 \\ \text { LANGUAGE: FAMILY } & \text { (Intercept) } & 4.429 \mathrm{e}-06 & 2.105 \mathrm{e}-03 \\ \text { FAMILY } & \text { (Intercept) } & 1.656 \mathrm{e}-05 & 4.070 \mathrm{e}-03 \\ \text { AREA } & \text { (Intercept) } & 2.455 \mathrm{e}-01 & 4.955 \mathrm{e}-01\end{array}$

3.2. AFFIX PREFERENCE. We asked whether the end-bias in neutralizing rules in this dataset could arise through a suffixing bias in the languages in the dataset. Suffixing is more common typologically than prefixing (Greenberg 1957, Dryer 2013, among others). Because morpheme contact provides a context for phonological alternations, the suffixing bias may indirectly result in a typological bias toward the development of phonological patterns at the ends of roots and stems, rather than the beginnings. Although we have no reason to think this would contribute to a particular end-bias for neutralizing rules as opposed to other rule-types, we explored two ways to test this possibility in this dataset. As we assembled the dataset we intentionally sought out exclusively prefixing languages to provide a comparison to the exclusively suffixing languages that appeared in the dataset, and we also coded the many 'mixed' languages by their inflectional affixing preference as coded in WALS (see above). In Figure 6, we show the distribution of neutralizing rules at beginnings versus ends of lexical domains for prefixing, mixed and suffixing languages. For all divisions of the data, there is a visual trend toward a greater number of neutralizing rules at the ends of lexical domains. If it were the case that neutralization in lexical domain edges is simply more likely at a stem-affix boundary (and therefore, the end-bias in this dataset is an artifact of more prevalent suffixing in the languages in the dataset), we would expect to find a reversal in this pattern in exclusively prefixing languages in the form of a bias toward having more neutralizing rules at the beginnings of lexical domains. This is not the case. 
Figure 6. End-bias in neutralizing rules by affixation preference.
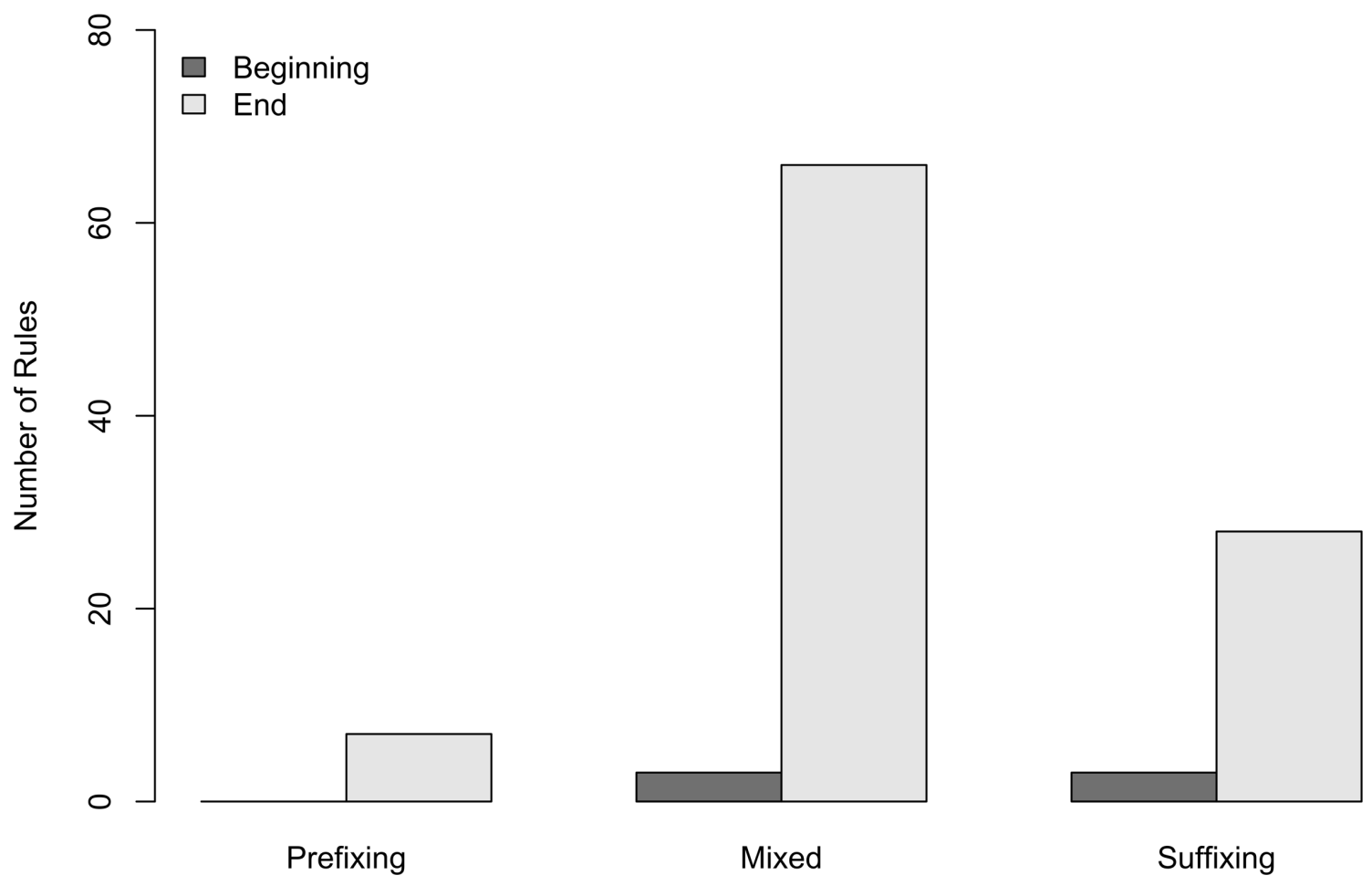

We statistically explored the explanatory value of affixation type by including a fixed factor AFFIXATION TYPE as an ordered factor with the three levels 'exclusively prefixing', 'mixed', 'exclusively suffixing' in the basic model given above, either alone or in interaction with RULE TYPE. This factor did not contribute significantly in either case to model fit using Chisquared log-likelihood tests $(\mathrm{p}>.05)$, indicating that this particular division of languages does not help the model predict the domain side that a rule targets.

As an alternative way to code the data which divides the set of rules into two approximately equal groups, we used the WALS coding for inflectional affix-bias to divide the dataset into those languages which are suffixing-dominant, versus those which are not. We constructed a two-level factor AFFIXATION PREFERENCE, where the level 'suffixing' combines the exclusively suffixing languages with the inflectionally suffixing-dominant languages (121 rules in total), while the level 'non-suffixing' combines the exclusively prefixing languages, the inflectionally prefixing-dominant languages and the languages in the dataset coded as having no inflectional affix preference (116 rules in total). The AFFIXATION PREFERENCE factor was not significant alone or in interaction with RULE TYPE, and did not contribute significantly to model fit as assessed by chi-squared log-likelihood tests $(p>.05)$. The consistency of the end-bias in rules suggests that the observed end-bias in neutralizing rules does not arise through asymmetries in affixation preferences in the dataset. 
3.3. EDGE ASYMMETRIES IN PHONETIC BIASES. As discussed in section 1 above, the broader causal hypothesis motivating this study is based in evidence that speakers tend to preserve phonetic cues that provide more information in lexical access, while tolerating reduction of lower information phonetic cues. Over diachronic time, this asymmetry should result in an output-oriented filter inhibiting the development of contrast-neutralizing rules at word beginnings, where cue information tends to be higher (Hall et al. 2016, 2018). But even if this hypothesis is borne out, there remain many other influences on the evolution of phonological rules. For example, word beginnings and ends are not subject to precisely the same distribution of articulatory or perceptual biases and so we expect the distribution of phonological rule types by word edge to differ just on that basis. For example, Blevins (2006) argues that a constellation of factors promotes the perception of devoicing at the ends of phrases, which can be phonologized as word-final devoicing. As expected on this basis, within this dataset devoicing patterns are more common at the ends of lexical domains than at the beginnings (see Fig 7).

Given that there are asymmetries in phonetic biases at beginnings versus ends of words, an edge asymmetry in the prevalence of neutralizing rules could theoretically arise if phonetic biases which preferentially apply to word ends just happen to be more likely to promote the development of contrast neutralizing rules. Under this hypothesis, the observed end-bias for neutralization across the diverse languages in this dataset could be fully accounted for through a universal property of some phonetic bias(es), instead of arising at least partially through a universal property of lexical processing which creates an information asymmetry across lexical domains. A thorough investigation of this hypothesis is not possible within this dataset. However, we can approach the question by noting that if the end-bias were fully accounted for through an asymmetry in the distribution of particular phonetic biases, the end-bias in neutralization would likely itself be concentrated in particular phonological rule categories. Instead, we find that the end-bias for neutralization is consistent across diverse processes and targets within this dataset. For example, above we showed above that while word-final coda consonants are common targets for neutralization through processes like devoicing and debuccalization, the end-bias for neutralization remains strong when coda-consonant modifying rules are removed from the dataset (Fig 5). In this section, we further divide the dataset into rough categories based on different phonological processes (see Brohan \& Mielke (2018) for relevant discussion).

Common general categories of rules in this dataset include consonant and vowel devoicing, segment deletions, place/voice/nasal assimilations, non-assimilatory changes in manner, and a range of other non-assimilatory changes in nasality, vowel/consonant place, laryngeal features or length. Rules in all of these categories appear at both lexical domain beginnings and ends in this dataset. Figure 7 shows the number of rules of these types at lexical domain beginnings versus ends, along with the proportion that are neutralizing. As we expect, some rule types are more common at one edge or the other, but within all these rule types, both the absolute and relative probability of neutralization tends to be higher at domain ends than beginnings.

As a further check that the overall edge-bias in the data is not being driven by a narrow range of rule types, we removed from the dataset all the rules from three common types deletion, devoicing and epenthesis - and re-tested for an end-bias in neutralization. We find that the end-bias for neutralization remains significant ( $p<.01$, model output not shown), despite the 
fact that the remaining rules comprise a diverse set of processes and targets. The consistency of the end-bias in neutralization across disparate rule types is expected if it arises through a general processing bias that can affect the diachronic development of any phonological rule, but is more surprising if it is driven by particular phonetic biases acting at word-ends. As a parallel example, Futrell et al. (2015) found support for a proposed universal processing bias toward minimizing phrasal dependency lengths on the basis of finding a consistent pattern of dependency-length minimization across a large, syntactically diverse set of languages.

Figure 7. Consistency of end-bias in neutralizing rules over different rule types. 'Assimilation' includes voicing, nasal, and place assimilations; 'Devoicing' includes both obstruent and sonorant devoicing; 'Manner' includes non-assimilatory changes such as spirantization or hardening; 'Other' covers the remainder of rules in the dataset, most of which are nonassimilatory changes in place, nasality, length or laryngeal features.
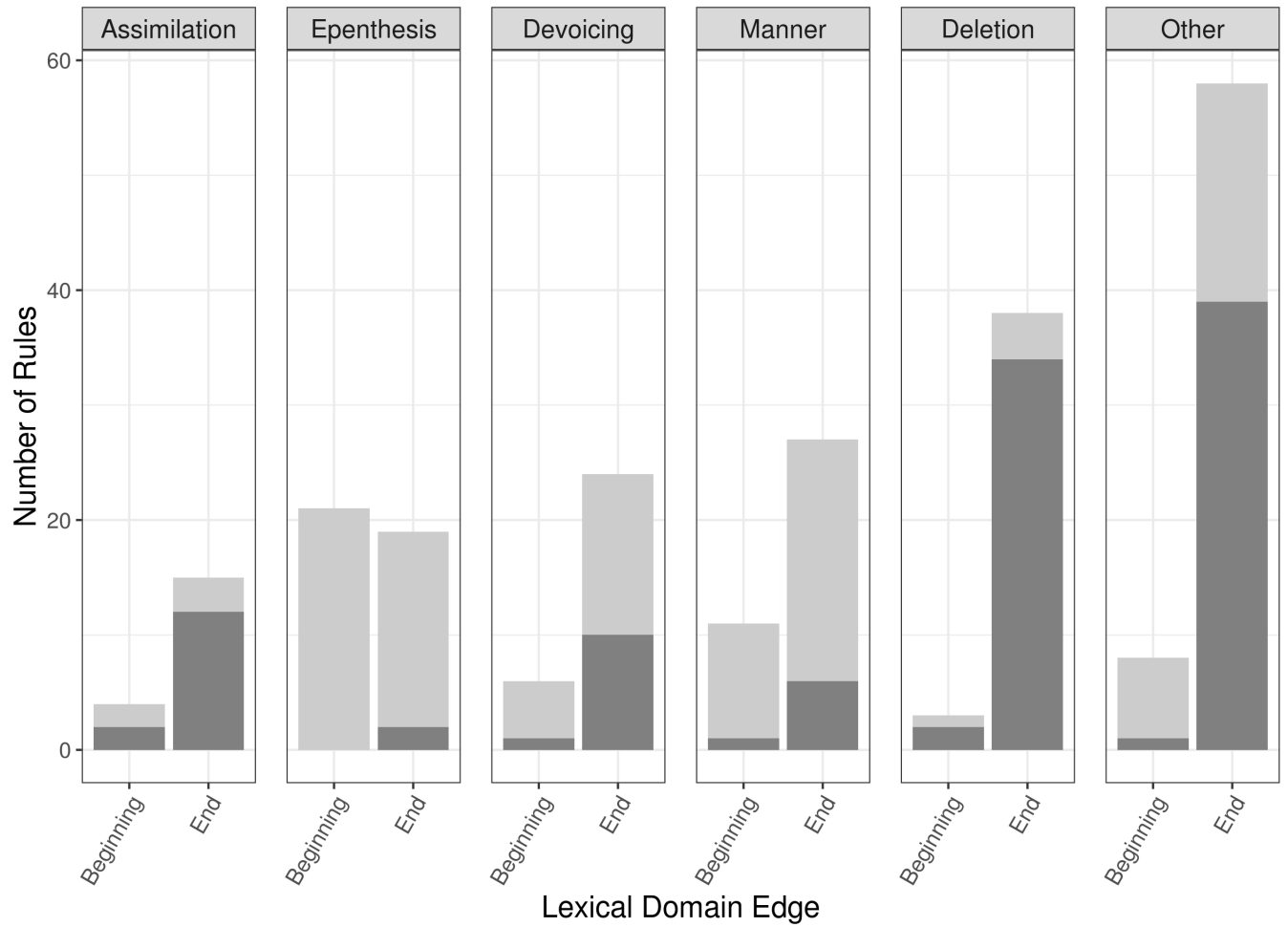

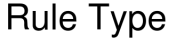

Non-Neutralizing Neutralizing

4. DiSCUSSION. We tested a specific prediction based in the broad hypothesis that phonological grammars are less likely to evolve contrast-reducing rules near the beginnings of lexical domains, where phonetic cues tend to be more informative in lexical access (Houlihan 1975, reviewed in Hall et al. 2016). Using a dataset of 237 phonological rules from an areally and genetically diverse set of 50 languages, we found that phonemically neutralizing rules are in fact significantly less likely to be defined on the beginnings of lexical domains than the ends, which is consistent with this broad hypothesis.

The kind of typological data we employed for this study comes with important caveats. Although we included controls for non-independence in datapoints based in genetic and areal relationships, there are other potentially biasing factors in the data that are not currently possible 
to control, such as the fact that most authors of these grammars are native speakers of a western European language, and trained in the same modern linguistic tradition. Further, creating a coherent dataset from disparate grammars requires many interdependent decisions about how to map descriptions in grammars into consistent categories for analysis, which introduces considerable 'researcher degrees of freedom' (Simmons et al. 2011). As a result, if another set of phonologists carried out the same task using the same 50 grammars they would be likely to produce a slightly different dataset. As described in Methods above, our operational response to this issue of potential variation in coding strategies was to systematically bias our coding decisions to be more conservative with respect to the tested hypothesis.

While it is important to keep these caveats in mind, the end-bias for neutralizing rules that we find in this data is sufficiently robust that we are confident that it is unlikely to arise through error, for example from our particular strategy in building the dataset, from a systematic bias on the part of field linguists, or from sampling error within the set of available grammars for languages in the world. This end-bias is consistent in all tested language families, in all tested linguistic areas, across a wide range of phonological rule types, and within virtually all languages (Figure 3a, b; Figure 7). The linguistic variation in the dataset ranges across languages with a variety of word-formation strategies, such as isolation, agglutination or polysynthesis, and across languages that are exclusively suffixing, prefixing, or of mixed type. Although the size of this dataset does not provide the statistical power to test the significance of the end-bias pattern within all of these possible linguistic subgroupings, its apparent consistency across the great variety of languages within this dataset remains striking.

How does this end-bias arise? A large of body of variationist research into the causes and pathways of sound change suggests that consistent, synchronic asymmetries in the fine-grained details of usage can potentially provide the seeds for parallel, diachronic changes in grammar (for recent work in this area see e.g. Beddor et al. 2018, Petre \& Van de Velde 2018). A synchronic asymmetry that may underlie our findings here is based in evidence that speakers tend to hyperarticulate lexically informative phonetic cues, while conversely reducing less lexically informative cues (reviewed in Hall et al. 2016, 2018). For example, Wedel, Nelson and Sharp (2018) show that within the Buckeye corpus of conversational English speakers hyperarticulate cues to word-initial stops, and to initial-syllable vowel place if those cues distinguish the target word from a minimal-pair competitor (e.g., pat $\sim$ bat, meet $\sim$ mitt). Using the same corpus, Cohen Priva (2015) showed that the probability that particular consonants would be deleted in word-final position was inversely related to each consonant's informativity, that is, the average amount of lexically disambiguating information it contributes in word-final position.

Because listeners process speech incrementally, developing hypotheses progressively about the intended word as the signal unfolds, phonetic cues early in the word provide on average more disambiguating information than cues late in the word (van Son \& Pols 2003, Magnuson et al. 2007). Putting this together, the lower average information late in the word should promote, on average, greater phonetic reduction and ambiguity in usage word-finally than word-initially. Given a systematic bias toward domain final reduction, contrast-reducing phonological rules should be more likely to evolve in lexical domain-final positions, than in lexical domain initial positions (see e.g. Ohala 1989, Blevins 2004, Beddor et al. 2018 for a sample of the range of discussions of the role of synchronic variation in the diachronic development of phonological patterns). 
In cognition, the progressive incorporation of perceptual cues to update hypotheses is not limited to language processing (see e.g., Henderson 2017 and references therein for reviews of work on cue integration in visual processing). Likewise, it is plausible that incremental processing of cues in the communication channel is a common feature of lexical access in all human languages. In any language then, a given phonetic cue-type will tend to carry more information when it appears domain-initially than domain-finally. Taken together with the data we have presented here, we predict on this basis that the lexical domain end-bias in contrastreducing phonological rules is likely to be a 'strong statistical universal', that is, a property that is widely and robustly shared across the entire range of human languages (Dryer 1998; see Futrell et al. (2015) for a parallel example in sentence processing). Correspondingly, the proposed causal link between incremental processing and an end-bias in contrast-reducing rules provides predictions about what conditions could lead to exceptions to this pattern. In particular, this model predicts that exceptions are likely to be associated with uncommon informational contexts: for example, an initial neutralization pattern might be more likely to develop if the targeted cues in word-initial position consistently provide little disambiguating information in lexical access (see below).

4.1. FURTHER DIRECTIONS. An unexpected finding was that significantly more rules overall target the ends of lexical domains. One potential, simple explanation is that the set of rules we categorized as 'non-neutralizing' still contains many rules that reduce phonetic cue perceptibility, such as word-final sonorant devoicing. If as described above, the ultimate source of the end-bias is a tendency in usage to reduce those cues which provide less information in lexical access, we expect rules which have the effect of perceptually reducing low-information cues will also be end-biased even if they do not result in full neutralization. However, in the absence of language-specific articulatory and perceptual data, we cannot predict with great confidence which non-neutralizing rules in fact reduce phonetic cue perceptibility for a listener in a particular language. Nonetheless, as an informal step to ask if this interpretation may be on the right track, we coded rules within the 'non-neutralizing' subset as 'phonetically-reducing' if they reduce a cue to phoneme identity which we expect to be otherwise highly perceptible. Specifically, we operationally defined 'phonetically reducing' for this task as any rule that devoiced a sonorant, or lenited a stop through debuccalization, spirantization, or non-release. Twenty-four non-neutralizing rules fit this criterion; 6 of those rules were defined on the beginning of a lexical domain, while 18 were defined on an end. When we transferred these rules from the 'non-neutralizing' to the 'neutralizing' category and re-tested for a correlation with domain side, we found that the association of non-neutralizing rules with the end of lexical domains was strongly reduced, although still significant $(\mathrm{p}=.03)$. This shift is at minimum consistent with the hypothesis that contrast-reducing rules are relatively more likely to develop late in lexical domains - and conversely, that rules which do not influence perceptibility of contrasts may not be asymmetrically associated with lexical domain sides. An adequate test of this hypothesis will require more detailed, phonetically-grounded data.

Phonologists have argued that in addition to an asymmetry in active neutralization patterns across the word, static patterns also reveal a greater range of phonemic contrasts early in the word (e.g., Houlihan 1975, Beckman 1997, Hall et al. 2016). This appeared to be borne out within the set of grammars in this dataset: we noted many descriptions in which particular contrasts were reported to only appear root- or word-initially, or within the first syllable. However, because many of the grammars in our dataset did not directly address the distribution 
of contrasts across the word, we concluded that this particular collection of grammars is not wellsuited for a formal test of this related hypothesis. Recall that to ensure that our dataset contained information relevant to our question, we employed a criterion that a grammar must have at least two rules defined on a lexical-domain side. Similarly, a dataset designed to test the hypothesis that static contrast patterns favor word initial positions could be generated using the criterion that an included grammar must mention at least one positional contrast asymmetry.

We identified several word-initial neutralization patterns in our sample of grammars which did not fit our inclusion criteria because they were limited to particular morpho-syntactic contexts, rather than being phonologically general (see the Chichewa example above). Initial consonant mutation in Celtic is a generally familiar example of this sort, in which a potentially neutralizing change only occurs in particular syntactic contexts (Ball \& Muller 2012). This leads us to ask whether word-initial neutralization patterns may be more likely to develop (or be retained over time) if the pattern itself conveys disambiguating information at a different structural level, such as that of morphosyntax. This hypothesis could be tested using the same grammar-sampling strategy we have employed here - although the fact that there were not many patterns of this sort in our sample of 50 languages suggests that a more intensive search of grammars would be necessary to achieve sufficient statistical power.

We noted above that we coded rules as 'neutralizing' if they could create surface homophony given the phonotactics of the language - but that we did not ask whether the rule created any actual homophony. Just as a phonological system may evolve in ways that support lexical contrast relationships in the existing lexicon (e.g., Blevins \& Wedel 2009, Wedel et al. 2013, this work), the lexicon may also evolve in response to existing contrast relationships within the phonological system (Graff 2012). This allows us to generate the following set of hypotheses: (i) if a neutralizing rule exists in a grammar, the lexicon will have fewer minimal pairs rendered homophonous by application of the rule than would be expected given the phonotactics of the language; (ii) this tendency should be stronger for word-initial neutralization rules than for word-final neutralization rules. As an example, the native vocabulary of Welsh is reported to have very few word pairs that are rendered homophonous by initial consonant mutation, although some of the consonant mutation patterns in Welsh are phonologically neutralizing (Roberts 2009). It would be interesting to ask more generally whether the lexicons in languages with morphosyntactically-informative initial neutralization patterns (e.g., Celtic and Chichewa) appear to be significantly structured to avoid lexical homophony from application of those initial neutralization rules.

5. CONCLUSION. Most phonologists already have an informal intuition that wordfinal contrasts are more apt to be neutralized than word initial contrasts. Given the striking and consistent preference for word-final neutralization patterns across the diverse languages in this dataset, it is not hard to see how this sense would arise just from the sample of grammatical patterns a linguist gains through experience (see, e.g., Figure 3a, b; Figure 4). Since a central task of modern phonology is to explain crosslinguistic markedness patterns, we might then ask why such a clear pattern has not been a more intensive subject of study, especially after the strong contributions to this area made in the 70s and 80s (Houlihan 1975, Houlihan \& Iverson 1979, Taft 1984) and subsequent work in the late 90s and early 2000s (Beckman 1997, Hume 1998, Mielke \& Hume 2001, Smith 2004). Part of the explanation may lie in the fact that dominant phonological theories of the time generated explanation through the interaction of innate synchronic mechanisms, and these mechanisms do not by themselves provide straightforward 
ways to integrate a usage-level effect of lexical processing over diachronic time into a theoretical account for a synchronic pattern. More recent approaches to explanation in phonology do specifically integrate interactions between synchronic and diachronic pathways, via models for how usage-level variation is shaped by production and perception biases, which in turn serves as input for grammaticalization over time (see e.g., Ohala 1989, Blevins 2004, Winter \& Wedel 2016, Sóskuthy \& Hay 2017; reviewed in Hall et al. 2016). The increasing availability and amounts of new data types, coupled with greater sophistication of analysis techniques (Bickel 2007), should allow these evolutionary models to be tested in increasingly complex ways in coming years. In particular, statistical analyses of large, diverse datasets can more rigorously test prior hypotheses (e.g., this study; Everett 2018), as well as reveal new patterns. As more statistical studies of the sort presented here are carried out, we anticipate that more patterns of this type may be discovered or confirmed. 


\section{REFERENCES}

Allopenna, Paul; James Magnuson; and Michael Tanenhaus. 1998. Tracking the time course of spoken word recognition using eye movements: Evidence for continuous mapping models." Journal of Memory and Language 38.419-439.

BAll, MARTIN; and NiCOLE Muller. 2012. The Celtic Languages. Routledge.

BECKMAN, JILL. 1997. Positional faithfulness, positional neutralisation and Shona vowel harmony. Phonology 14. 1-46.

Beddor, Patrice Speeter; Andries W. Coetzee; Will Styler; Kevin B. McGowan; and JULIE E. BOLAND. 2018. The time course of individuals' perception of coarticulatory information is linked to their production: Implications for sound change. Language 94, no. 4. 931-968.

BICKEL, BALTHASAR. 2007. Typology in the 21st century: Major current developments. Linguistic Typology 11.239-51. DOI: 10.1515/LINGTY.2007.018.

BiCKEL, BALTHASAR; and JOHANNA NiCHOLS. 2017. The Autotyp Genealogy and Geography Database. Online: http://www.autotyp.uzh.ch/ (accessed August 2018).

BLEVINS, JULIETTE. 2004. Evolutionary phonology: The emergence of sound patterns. Cambridge: Cambridge University Press.

BLEVINS, JULIETTE. 2006. A theoretical synopsis of evolutionary phonology. Theoretical Linguistics 32. 117-165.

BLEVINS, JULIETTE; and ANDREW WEDEL. 2009. Inhibited sound change: An evolutionary approach to lexical competition. Diachronica 26.143-183.

Brohan, ANTHONY; and JefF MielKe. 2018. Frequent segmental alternations in P-base 3. Phonological typology. Walter de Gruyter, 196-228.

BRown, Roger; and DAVID MCNEILL. 1966. The "tip of the tongue" phenomenon." Journal of Verbal Learning and Verbal Behavior 5.325-337.

BRUNER, JEROME; and DONALD O'DOWD. 1958. A note on the informativeness of parts of words." Language and Speech 1.98-101.

Buz, Esteban; Michael K. TANenhaus; and T. Florian JAEger. 2016. Dynamically adapted context-specific hyper-articulation: Feedback from interlocutors affects speakers' subsequent pronunciations. Journal of memory and language 89.68-86.

COHEN PRIVA, URIEL. 2015. Informativity affects consonant duration and deletion rates. Laboratory Phonology 6.243-278.

Dahan, Delphine; James Magnuson; Michael Tanenhaus; and Ellen Hogan. 2001. Subcategorical mismatches and the time course of lexical access: Evidence for lexical competition. Language and Cognitive Processes 16.507-534.

Downing, LAurA. J., and Al J. D. MtenJe. 2017. The Phonology of Chichewa. Oxford University Press.

DRYER, MATTHEW S. 1998. Why statistical universals are better than absolute universals. Papers from the 33rd Annual Meeting of the Chicago Linguistic Society. 123 - 45.

DRYER, MATTHEw. 2013. Prefixing vs. Suffixing in Inflectional Morphology. In Dryer \& Haspelmath. Online: http://wals.info/chapter/26.

Dryer, MATTHEW; and MARTin HASPELMATH. 2013. The World Atlas of Language Structures Online. Leipzig: Max Planck Institute for Evolutionary Anthropology. Online: http://wals.info.

EveretT, CALEB. 2018. The global dispreference for posterior voiced obstruents: A quantitative assessment of word-list data. Language 94.e311-e323. 
Fernald, AnNe; Daniel Swingley; and John Pinto. 2001. When half a word is enough: Infants can recognize spoken words using partial phonetic information." Child development 72.1003-1015.

FUTRELL, RICHARD; KYLE MAHOWALD and EDWARD GIBSON. 2015. Large-scale evidence of dependency length minimization in 37 languages. Proceedings of the National Academy of Sciences 112.33: 10336-10341.

Graff, Peter Nepomuk Herwig Maria. 2012. "Communicative efficiency in the lexicon." PhD diss., Massachusetts Institute of Technology.

GreENBERG, JosePH. 1957. Essays in linguistics. Chicago, IL: University of Chicago Press.

Hall, Kathleen CurRie; Elizabeth Hume; T. Florian JaEger; and AndReW Wedel. 2016. The message shapes phonology. Ms. University of British Columbia, University of Canterbury, University of Rochester \& University of Arizona. PsyArXiv. psyarxiv.com/sbyqk.

Hall, Kathleen Currie; Elizabeth Hume; T. Florian Jaeger; and AndReW Wedel. 2018. The role of predictability in shaping phonological patterns." Linguistics Vanguard 4.

HAMMARSTRÖM, HARALD \& FORKEL, ROBERT \& HASPELMATH, MARTIN. 2018. Glottolog 3.3. Jena: Max Planck Institute for the Science of Human History. (Available online at http://glottolog.org, Accessed on 2018-09-01.)

Henderson, John M. 2017. Gaze Control as Prediction. Trends in Cognitive Sciences, Vol. 21, No. 1, 15-23.

Houlihan, KATHLEEN. 1975. The role of word boundary in phonological processes. Austin, TX: University of Texas dissertation.

HOULIHAN, KATHLEEN; and GREGORY IVERSON. 1979. Functionally-constrained phonology. In Dinnsen, 50-73.

Hume, ElizABETH. 1998. Metathesis in phonological theory: The case of Leti. Lingua 104. 14786.

ITO, JUNKO. 2018. Syllable theory in prosodic phonology. London: Routledge.

Jaeger, T. Florian; Peter GrafF; William Croft; and Daniel Pontillo. 2011. Mixed effect models for genetic and areal dependencies in linguistic typology. Linguistic Typology 15.281-319.

Magnuson, James; James Dixon; Michael TAnenhaus; and Richard Aslin. 2007. The dynamics of lexical competition during spoken word recognition. Cognitive Science 31.133-156.

MARSLEN-Wilson, WiLliaM; and Pienie ZwitserloOD. 1989. Accessing spoken words: The importance of word onsets." Journal of Experimental Psychology: Human perception and performance 15.576 .

MielKe, JefF; and ElizABETh Hume. 2001. Consequences of word recognition for metathesis. Surface Syllable Structure and Segment Sequencing. Leiden: HIL, 135-158.

Miller, GeOrge; and ElizABETh Friedman. 1957. The reconstruction of mutilated English texts. Information and Control 1. 38-55. DOI: 10.1016/S0019-9958(57)90061-X.

Nooteboom, SiEB. 1981. Lexical retrieval from fragments of spoken words: beginnings vs. endings. Journal of Phonetics 9.407-424.

OHALA, JoHN J. 1989 "Sound change is drawn from a pool of synchronic variation." Language change: Contributions to the study of its causes: 173-198.

Petré, PeTER; and FreEK VAN DE VELDE. 2018. The real-time dynamics of the individual and the community in grammaticalization. Language 94, no. 4: 867-901. 
RoBerts, SeAn. 2009. Welsh mutation and lexical dispersion. In Keven Laland, Gillian Brown, Luke Rendell, Lewis Dean \& Tamsin Saxton (eds.) Proceedings of the 1st European Human Behaviour and Evolution Association Conference, St. Andrews, UK.

RoETTGER, Timo B., 2019. Researcher degrees of freedom in phonetic research. Laboratory Phonology: Journal of the Association for Laboratory Phonology, 10(1), p.1.

ROMERO-MÉnDEZ, RoBERTO. 2008. A Reference Grammar of Ayutla Mixe. Tukyo'm ayuujk (Doctoral dissertation, Tesis de Doctorado no publicada. Universidad de Buffalo).

Schad, DANiEl J., Sven Hohenstein, Shravan VASISHTH; and ReINHOLD KLIEGL. 2018. How to capitalize on a priori contrasts in linear (mixed) models: A tutorial. arXiv preprint arXiv:1807.10451 (2018).

Seyfarth, SCOTT., BUZ, ESteban., \& JAEGER, T. Florian. 2016. Dynamic hyperarticulation of coda voicing contrasts. The Journal of the Acoustical Society of America, 139 (2), EL31EL37.

Shannon, Claude. 1949. Communication in the presence of noise. Proceedings of the IRE 37. $10-21$.

SIMMONS, JOSEPH; LEIF NELSON; and URI SIMONSOHN. 2011. False-positive psychology: Undisclosed flexibility in data collection and analysis allows presenting anything as significant. Psychological Science 22.1359-1366.

SMITH, JENNIFER. 2004. Making constraints positional: toward a compositional model of CON. Lingua 114. 1433-1464.

SÓSKUTHY, MÁRTON; and JEN HAY. 2017. Changing word usage predicts changing word durations in New Zealand English. Cognition 166. 298-313.

TAFT, LORI. 1984. Prosodic constraints and lexical parsing strategies. Amherst: University of Massachusetts, Amherst dissertation.

TYLER, LORRAINE. 1984. The structure of the initial cohort: Evidence from gating. Perception \& Psychophysics 36.417-427.

VAn Son, R. J. J. H.; and LOUIS POLS. 2003. How efficient is speech. In Proceedings of the institute of phonetic sciences, 25.171-184.

WARnER, NATASHa; Allard JONGMAN; JOAN SERENO; and RACHÈl KEMPS. 2004. Incomplete neutralization and other sub-phonemic durational differences in production and perception: Evidence from Dutch." Journal of Phonetics 32.251-276.

WEDEL, ANDREW. 2012. Lexical contrast maintenance and the development of sublexical contrast systems. Language and Cognition, 4: 319-355.

WEDEL, ANDREW; ABBY KAPLAN; and SCOTT JACKSON. 2013. High functional load inhibits phonological contrast loss: A corpus study. Cognition 128.179-186.

WEDEL, ANDREW; NOAH NELSON; and REBECCA SHARP. 2018. The phonetic specificity of contrastive hyperarticulation in natural speech. Journal of Memory and Language 100.61-88.

WiNTER, BODO, and ANDREW WEDEL. 2016. The co-evolution of speech and the lexicon: The interaction of functional pressures, redundancy and category variation. Topics in Cognitive Science 8: 503-513.

[wedel@email.arizona.edu]

[ussishki@email.arizona.edu]

[adamking@email.arizona.edu] 